\title{
Strain-Specificity and Disease- Specificity of Probiotic Efficacy: A Systematic Review and Meta-Analysis
}

\author{
Lynne V. McFarland ${ }^{1 *}$, Charlesnika T. Evans ${ }^{2,3}$ and Ellie J. C. Goldstein ${ }^{4}$ \\ 'Department of Medicinal Chemistry, School of Pharmacy, University of Washington Medical Center, Seattle, WA, United \\ States, ${ }^{2}$ Department of Preventive Medicine and Center for Healthcare Studies, Feinberg School of Medicine, Northwestern \\ University, Chicago, IL, United States, ${ }^{3}$ Department of Veterans Affairs (VA), Center of Innovation of Complex Chronic \\ Healthcare (CINCCH), Edward Hines Jr VA Hospital, Hines, IL, United States, ${ }^{4}$ RM Alden Research Laboratory, David Geffen \\ School of Medicine at UCLA, Los Angeles, CA, United States
}

Background: As the use and diversity of probiotic products expands, the choice of an appropriate type of probiotic is challenging for both medical care professionals and the public alike. Two vital factors in choosing the appropriate probiotic are often ignored, namely, the probiotic strain-specificity and disease-specificity for efficacy. Reviews and meta-analyses often pool together different types of probiotics, resulting in misleading conclusions of efficacy.

OPEN ACCESS

Edited by: Miguel Cacho Teixeira, Universidade de Lisboa,

Portugal

Reviewed by:

Takako Osaki,

Kyorin University, Japan

Ruixue Huang,

Central South University, China

*Correspondence:

Lynne V. McFarland

Ivmcfarl@u.washington.edu

Specialty section:

This article was submitted to Infectious Diseases - Surveillance,

Prevention and Treatment, a section of the journal

Frontiers in Medicine

Received: 06 December 2017 Accepted: 13 April 2018

Published: 07 May 2018

Citation:

McFarland LV, Evans CT and Goldstein EJC (2018) StrainSpecificity and Disease-Specificity of Probiotic Efficacy: A Systematic Review and Meta-Analysis. Front. Med. 5:124. doi: 10.3389/fmed.2018.00124
Methods: A systematic review of the literature (1970-2017) assessing strain-specific and disease-specific probiotic efficacy was conducted. Trials were included for probiotics with an identifiable strain (either single strain or mixtures of strains) that had at least two randomized, controlled trials for each type of disease indication. The goal was to determine if probiotic strains have strain and/or disease-specific efficacy.

Results: We included 228 trials and found evidence for both strain specificity and disease specificity for the efficacy of specific probiotic strains. Significant efficacy evidence was found for 7 (70\%) of probiotic strain(s) among four preventive indications and 11 (65\%) probiotic strain(s) among five treatment indications. Strain-specific efficacy for preventing adult antibiotic-associated diarrhea was clearly demonstrated within the Lactobacillus species [e.g., by the mixture of Lactobacillus acidophilus CL1285, Lactobacillus casei LBC80R, and Lactobacillus rhamnosus CLR2 (Bio-K+ ${ }^{\circledR}$ ), by L. casei DN114001 (Actimel $^{\circledR}$ ) and by Lactobacillus reuteri 55730], while other Lactobacillus strains did not show efficacy. Significant disease-specific variations in efficacy was demonstrated by L. rhamnosus GG and Saccharomyces boulardii CNCM I-745, as well as other probiotic strains.

Conclusion: Strong evidence was found supporting the hypothesis that the efficacy of probiotics is both strain-specific and disease-specific. Clinical guidelines and metaanalyses need to recognize the importance of reporting outcomes by both specific strain(s) of probiotics and the type of disease. The clinical relevance of these findings indicates that health-care providers need to take these two factors into consideration when recommending the appropriate probiotic for their patient.

Keywords: strain specificity, disease specificity, probiotic strains, meta-analysis, pooling data, antibioticassociated diarrhea, Clostridium difficile, Saccharomyces, Lactobacillus 


\section{INTRODUCTION}

The use of probiotics has become increasingly popular across the world and probiotic use in hospitalized patients may reach as high as $55 \%$ in admitted patients (1). Probiotics are defined as "live microorganisms that, when administered in adequate amounts, confer a health benefit on the host" (2), but unfortunately, this definition does not provide any practical guidance when choosing a probiotic. Decades of clinical trials have provided a foundation for a diverse array of probiotics (either single strain or multistrain mixtures), but matching the appropriate probiotic strain or mixture to the patient's need has been challenging (3).

Recently, research has supported the concept that not all probiotics are equally effective, but a consensus has not been uniformly reached as to which probiotic product should be used for specific disease conditions $(4,5)$. Distinguishing the different probiotic products is challenging due to differences in their mechanisms-of-action, manufacturing processes, quality control of the product, and efficacy by different strain(s). Differences in strain-specific efficacy began to be reported in 2010 as genomic analysis characterized bacterial and fungal strains in greater detail $(6,7)$. International probiotic guidelines and recognized experts in the field started to recommend using strain designations when reporting outcomes in clinical trials so that strain-specific efficacy can be determined, but this recommendation has not been uniformly followed $(2,4,8,9)$. In vitro assays and animal model data indicate efficacy differs from strain to strain among tested potential probiotic strains (10). Screening tests include determining survival from ingestion to the target organ (most commonly the intestinal tract) using pharmacokinetic studies, ability to interfere with pathogenesis (typically using animal models of disease), and stability of the microbe preparation (11). Domig et al. screened over 127 different Lactobacillus strains and found only $3 \%$ had potential as a probiotic, based on survival to the target organ and ability to resist bile and stomach acidity (12). An in-depth investigation of over 170 species of Lactobacillus found significant variation in sensitivities to antibiotics and ability to act as a probiotic candidate (7).

Different probiotic strains have different mechanisms-of-action against pathogens including: bacteriocins that directly kill or inhibit specific pathogens, the destruction of pathogenic toxins, reinforcement of the integrity of host cells (such as intestinal enterocytes), interference with pathogen attachment to host cells (termed "colonization resistance" or the barrier effect), restoration of dysbiosis of the normal microflora, and the ability to upregulate or downregulate the immune response (13). Not all probiotic strains have each of these capabilities, but several probiotics possess multiple anti-pathogen properties, such as Saccharomyces boulardii CNCM I-745 (14). The presence or absence of the different factors by different strains of probiotics may also explain why some probiotics are effective in some types of diseases, yet, are not effective in a different type of disease.

The goal of this systematic review and meta-analyses is to explore the efficacy of probiotics by strain and disease specificity. We gathered evidence from intervention trials randomizing adult or children subjects to either a probiotic or a control for the prevention or treatment of specific diseases.

\section{METHODS}

\section{Search Strategy}

Prior meta-analyses were used as data sources and an updated search (through February 2017) was conducted for subsequent trials $(15,16)$. A search of PubMed (1960-2017), EMBASE (1974-2017), Cochrane Database of Systematic Reviews (1990-2017), ISI Web of Science (2000-2017), and three on-line clinical trial registries: Cochrane Central Register of Controlled trials, ${ }^{1}$ MetaRegister of Controlled Trials, ${ }^{2}$ and National Institutes of Health $^{3}$ was conducted. Bibliographies of all relevant studies and conference abstracts were also reviewed. Search terms included: probiotics, randomized clinical trials (RCTs), antibiotic-associated diarrhea (AAD), Clostridium difficile infections (CDI), irritable bowel syndrome (IBS), inflammatory bowel disease (IBD), Helicobacter pylori, nosocomial infections, travelers' diarrhea, and acute pediatric diarrhea.

\section{Inclusion/Exclusion Criteria}

Randomized, controlled trials in adults or children were included if they were of high quality, well-described, with defined outcomes. RCTs were also only included for probiotics with identifiable strain(s) and there were at least two RCTs within specific disease indications. Indications with the most robust numbers of trials were for the prevention (pediatric or adult AAD, CDI, nosocomial infections, and travelers' diarrhea) or treatment (CDI, IBD, IBS, $H$. pylori infections, and acute pediatric diarrhea) of disease. Non-English articles were translated and included. Disease indications with sparse data for specific probiotic strain or mixtures of strains were not included in this review. Studies were included only if they were RCTs and graded "strong strength" using standard methodology to assess strength of evidence from intervention trials (17). Additional exclusion criteria included: reviews, kinetic or safety studies, non-randomized trials, case-control studies, duplicate reports, and trials with insufficient descriptions of the type of probiotic, preclinical studies, or mechanisms of action studies. All RCTs were reviewed by all three co-authors.

\section{Probiotic Strain Designations}

As many clinical trials often only report the genus and species of probiotic used but not the specific strain, and taxonomy has shifted over time, we retrospectively linked the reported probiotic to the most current strain designation(s) using published articles on taxonomy or clinical trials, information from manufacturer's websites, or from communication with authors or sponsoring agencies. In some cases where the original strain was not reported in the original article but the manufacturer was known, the manufacturer was contacted to confirm that the same strains were used throughout the reported clinical trials. In other cases, trials were excluded if the strain was not reported in the original paper and the specific strain could not be retrospectively traced because the manufacturer was not reported and communications

${ }^{1}$ http://www.cochrane.org (Accessed: February 14, 2017).

${ }^{2}$ www.isrctn.com/page/mrct (Accessed: February 14, 2017).

${ }^{3}$ http://www.clinicaltrials.gov (Accessed: February 14, 2017). 
with the authors was either not productive or the authors did not remember the original source of the probiotic.

\section{Efficacy Assessments}

Efficacy was based on documenting at least two RCTs published in peer-reviewed journals that found a significant $(p<0.05)$ reduction of either the incidence of disease (prevention trials) or a reduction in clinical symptoms (treatment trials). We stratified our descriptive assessment of efficacy into two categories: (1) more net number of RCTs with significant outcomes/disease indication $(p<0.05)$ compared with non-significant findings and (2) strain(s) with at least two RCTs with significant outcomes/ disease indication, regardless of the number of non-significant trials. Total net number of significant RCTs was calculated summing the RCTs with significant efficacy findings subtracting total number of RCTs with non-significant $(p>0.05)$ outcomes.

\section{Meta-Analyses}

As the above descriptive method presents an unweighted assessment of efficacy by comparing the total number of RCTs with significant and non-significant findings, we also conducted meta-analyses when possible. This required at least two RCTs for each sub-group of the same strains of probiotic (or mixtures) within the same type of disease. Pooled relative risks (RR) and 95\% confidence intervals (CI) were calculated and heterogeneity was evaluated using the $I^{2}$ statistic, using standard methods (15).

\section{RESULTS}

A total of 2,366 abstracts were screened (2,345 from database searches and 21 from meeting abstracts or journals not included in the above databases). A total of 726 full articles were assessed (Figure 1). Of those, 373 were excluded due to either only one $\mathrm{RCT} /$ strain/disease $(n=214)$ or inability to identify the strain designation $(n=159)$. A total of 353 RCTs were found with at least two RCTs per sub-group ( $n=125$ preventive trials and $n=228$ treatment trials). Fourteen RCTs of AAD also documented CDI as a secondary outcome. Eighteen RCTs with $H$. pylori-infected patients designated eradication of $H$. pylori as their primary outcome, but also documented the prevention of adverse events

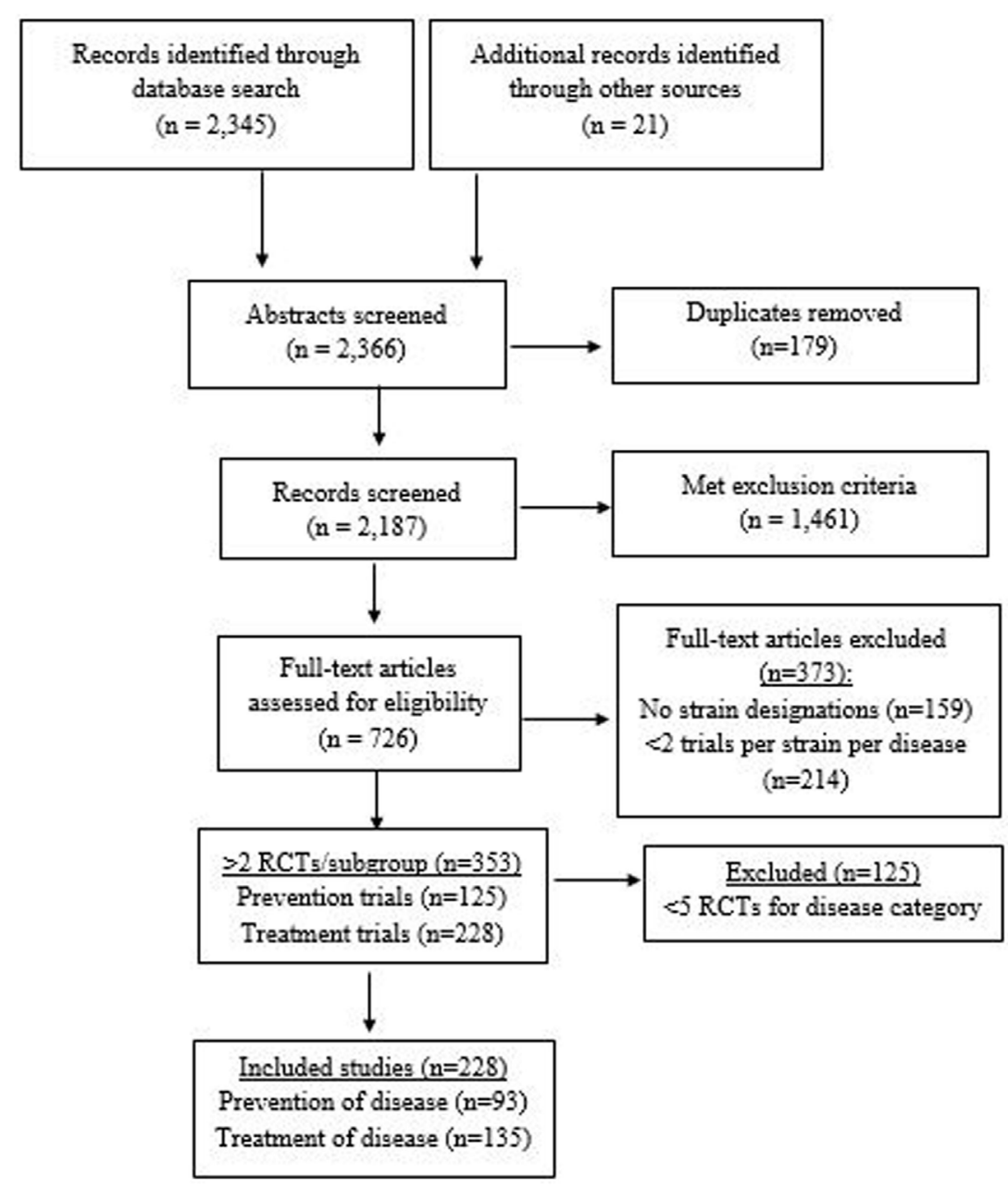

FIGURE 1 | PRISMA flow diagram of evaluated studies for randomized controlled trials for probiotic strain and disease-specificity, searched from inception of databases to February 2017. 
and/or AAD as additional outcomes. When disease indications with the most RCTs were selected (prevention of AAD, CDI, nosocomial infections, travelers' diarrhea, and treatment of IBD, IBS, CDI, acute pediatric diarrhea, and eradication of $H$. pylori), a total of 228 RCTs were included in this review. Probiotic trials with sparse data for each strain/disease indication subgroup were excluded $(n=125)$. A total of 25 different types of probiotics (15 single strained probiotics and 10 multi-strained mixtures) were assessed.

\section{Determination of Strain-Specificity Strain Designations and Shifting Taxonomy}

We found several challenges when identifying probiotic strain types from RCTs conducted over time: (1) shifting taxonomy of bacterial and fungal nomenclature as more precise and definitive tools (such as PCR probes and genomic sequencing) have been developed, (2) the lack of a global standard for naming strains, and (3) the incomplete identification of probiotic strains in reported RCTs publications (18). Strains are designated by a variety of naming regimes including manufacturer codes, depository numbers [such as American Type Culture Collection (ATCC) or Collection Nationale de Cultures de Microorganisms (CNCM)], or by the person isolating the original strain (for example, Lactobacilli casei Shirota). Genomic phenotyping has shifted microbes from one group to another or reclassified them into separate groups (such as $S$. boulardii CNCM I-745 Florastor $^{\circledR}$ versus $S$. boulardii Kirkman) (6) or the separation of Lactobacillus acidophilus into 20 separate Lactobacillus species groups (10). Examples of different types of probiotic products whose taxonomy has changed over the years are presented in Table 1. As the brand names of probiotic products often vary by country or by formulation, we present only the most commonly used brand names. Our initial literature search found over 700 RCTs for probiotics and various clinical indications. Typically, many published trials and meta-analyses reported the probiotic either on a genus (e.g., "a Lactobacillus probiotic") or on a species level (e.g., L. acidophilus), but did not provide the specific strain designation (e.g., L. acidophilus CL1285).

\section{Lactobacillus Strains}

To examine if strain-specificity exists for Lactobacillus spp., we reviewed the literature for RCTs of various Lactobacillus strains. We found only one RCT that directly compared two different strains of the same species (L. casei). Dietrich et al. compared two similar commercial products (Actimel ${ }^{\circledR}$ with L. casei DN-114001 and Yakult ${ }^{\circledR}$ with L. casei Shirota) for the prevention of AAD (19). One strain (L. casei DN-114001) was significantly more effective in reducing AAD incidence than the other $L$. casei strain (6.7 and $33.3 \%$, respectively, $p<0.05$ ). Unfortunately, direct strain to strain comparisons in the same RCTs for the same type of disease indications are extremely rare.

Next, we conducted a meta-analysis of RCTs testing probiotics within the same genus (Lactobacillus) for the prevention of AAD to determine if there is documented strain-specificity. We found 22 RCTs for the prevention of AAD in adults and used subgroup analyses for each of the six different Lactobacillus species.
As shown in Figure 2, only four of six types of Lactobacillus strains significantly prevented AAD in adults. Pooled data from two RCTs using L. casei DN-114001 shows a significant reduction of AAD $\left(\mathrm{RR}=0.32,95 \% \mathrm{CI} 0.16,0.63, I^{2}=0 \%\right)(19,20)$. Pooled data from three RCTs using L. reuteri ATCC 55730 also showed a significant reduction in the incidence of $\mathrm{AAD}(\mathrm{RR}=0.35,95 \% \mathrm{CI} 0.20,0.61$, $\left.I^{2}=0 \%\right)(21-23)$. In comparison, another strain (L. rhamnosus GG) did not show significant efficacy when data from six RCTs are pooled together $\left(\mathrm{RR}=0.55,95 \%\right.$ CI $\left.0.25,1.18, I^{2}=73 \%\right)$ (24-29). One study using L. rhamnosus GG reported the results of two trials, but only one had data on AAD (27). The mixture of three strains of Lactobacillus spp. (L. acidophilus CL1285, L. casei LBC80R, L. rhamnosus CLR2 or Bio-K+ ${ }^{\circledR}$ ) showed a significant reduction in $\mathrm{AAD}\left(\mathrm{RR}=0.56,95 \% \mathrm{CI} 0.40,0.79, I^{2}=51 \%\right)$ from data pooled from three trials with four intervention arms (30-32). Another mixture of L. acidophilus La5 and B. lactis Bb12 showed significant reduction of AAD in six RCTs in adult patients $\left(\mathrm{RR}=0.67,95 \% \mathrm{CI} 0.47,0.94, I^{2}=19 \%\right)(33-38)$. In contrast, data from two trials using a mixture of two strains of Lactobacillus (L. rhamnosus R011 and L. helveticus R052) failed to find significant efficacy for the prevention of $\operatorname{AAD}(39,40)$.

\section{Saccharomyces Strains}

Saccharomyces boulardii CNCM I-745 is a fungal single-strain probiotic with well documented efficacy for a variety of diseases (14). To demonstrate strain-specificity, we found six RCTs for two similar Saccharomyces species in adults with IBS (41-46). Only two RCTs with S. boulardii CNCM I-745 $(41,42)$ had comparable outcome metrics (change in symptom scores) as the two RCTs with S. cerevisiae I-3856 $(45,46)$. A significant reduction in symptom scores is seen for S. boulardii CNCM I-745 [weighted mean difference $(\mathrm{WMD})=-0.72,95 \% \mathrm{CI}$ $\left.-1.18,-0.25, I^{2}=99.2 \%\right]$, but not for $S$. cerevisiae CNCM $\mathrm{I}-3856$ strain $\left(\mathrm{WMD}=-0.16,95 \% \mathrm{CI}-0.33,+0.01, I^{2}=97.7 \%\right)$. Unfortunately, no RCTs were found that directly compared S. boulardii CNCM I-745 to other strains of Saccharomyces or for any other disease indication.

\section{Determination of Disease-Specificity}

Another challenge is that the same probiotic strain or mixture of strains may be effective for one disease, and yet, not effective for other disease types. Indications for probiotic use are diverse, ranging from prevention of disease (for example, AAD, vaginitis, travelers' diarrhea, sepsis, atopic dermatitis), or preventing sideeffects of standard therapies for diseases (such as treatment of $H$. pylori or chemotherapy), to the treatment of acute diseases (such as C. difficile infections, acute pediatric or adult diarrhea, constipation) or treatment of chronic disease conditions [such as IBD, IBS, or obesity (3)].

To demonstrate disease specificity using one probiotic strain, we conducted a meta-analysis using only RCTs testing L. rhamnosus GG, and then pooled subgroups by disease type. As probiotic efficacy and disease characteristics may differ for adults and children, we assessed AAD in these two populations separately (47). Efficacy from 23 RCTs (24 treatment arms) were grouped by the type of disease indication into six groups: prevention of pediatric AAD (48-51), prevention of adult AAD (24-29), 
TABLE 1 | Changing taxonomy of probiotic strains over time.

\begin{tabular}{|c|c|c|}
\hline Probiotic brand name ${ }^{a}$ & Older designations & Current designations \\
\hline Bio-K $+{ }^{\circledR}$ & $\begin{array}{l}\text { L. acidophilus CL1285 and } \\
\text { L. casei LBC80R }\end{array}$ & $\begin{array}{l}\text { L. acidophilus CL1285 and } \\
\text { L. casei LBC80R and L. rhamnosus CLR2 }\end{array}$ \\
\hline Dicoflor ${ }^{\circledR}$ & L. rhamnosus GR1 and L. fermentum RC14 & L. rhamnosus GR1 and L. reuteri RC14 \\
\hline Florastor ${ }^{\otimes}$ & $\begin{array}{l}\text { Saccharomyces cerevisiae boulardii } \\
\text { S. boulardii lyo } \\
\text { S. boulardii } 17 \\
\text { S. boulardii Hansen CBS- } 5926\end{array}$ & S. boulardii CNCM I-745 (ATCC 74012) \\
\hline Probi $\mathrm{AB}^{\circledR}$ or ProViva ${ }^{\circledR}$ & L. plantarum & L. plantarum 299v (DSM 9843) \\
\hline Protecflor ${ }^{\circledR}$ & $\begin{array}{l}\text { B. longum RW001 and } \\
\text { L. rhamnosus R11 and } \\
\text { L. acidophilus R52 and } \\
\text { S. boulardii }\end{array}$ & $\begin{array}{l}\text { B. longum R175 (CNCM I-755) and } \\
\text { L. rhamnosus R11 (CNCM I-1720) and } \\
\text { L. helveticus R52 (CNCM I-1722) and } \\
\text { S. cerevisiae boulardii (CNCM I-1079) }\end{array}$ \\
\hline Protectis $^{\circledR}$ & $\begin{array}{l}\text { L. reuteri DSM } 55730 \text { or } \\
\text { L. reuteri SD } 2112 \text { or } \\
\text { L. reuteri ATCC } 55730\end{array}$ & L. reuteri DSM17938 or ATCC7938 (daughter strain) \\
\hline Yakult ${ }^{\circledR}$ & L. casei YIT9029 & L. casei Shirota \\
\hline- & Strept. faecalis & Enter. faecalis \\
\hline- & L. acidophilus La-1 & L. johnsonii ATCC 33200 \\
\hline- & B. infantis 35624 & B. longum spp. longum 35624 \\
\hline- & $\begin{array}{l}\text { B. lactis } \mathrm{Bb} 12 \text { or } \\
\text { B. lactis DSM15954 }\end{array}$ & B. animalis spp. lactis Bb12 (CNCM 3446) \\
\hline
\end{tabular}

${ }^{a}$ Brand names may vary by country or formulation, most common brand name given (-), no brand name.

ATCC, American Type Culture Collection, Manassas, VA, USA; B., Bifidobacterium; CBS, Centraal Bureau voor Schimmelcultures, Baarn, The Netherlands. CNCM, Collection Nationale de Cultures de Microorganismes (Institut Pasteur, Paris, France); DSM, Deutsche Sammlung von Mikroorganismen, Braunschweig, Germany; Entero., Enterococcus; L., Lactobacillus; nr, not reported; S., Saccharomyces; Strept., Streptococcus.

Crohn's disease (52-55), C. difficile infection $(27,29,49,56)$, other types of nosocomial infections (57-60), and travelers' diarrhea $(61,62)$. Three trials documented both the prevention of AAD and prevention of CDI $(27,29,49)$. As shown in Figure 3, the $L$. rhamnosus GG strain has significant efficacy for the prevention of pediatric AAD $(\mathrm{RR}=0.44,95 \%$ CI $0.21,0.95, p<0.05)$. However, L. rhamnosus GG is not effective for other five diseases. This meta-analysis clearly demonstrates the disease-specificity of one strain of probiotic.

\section{Practical Application of Strain and Disease Specificity}

Appreciating the importance of strain specificity and disease specificity, we reassessed reviews and meta-analyses to determine if these two factors were accounted for in their analysis and conclusions. Many meta-analyses did not account for strainspecificity correctly, as different strains were pooled within the same subgroup (63-68) and some grouped probiotics only at a genus-level (69). One meta-analysis for the prevention of 
Study

ID

L casei DN-114001

Hickson 2007

Dietrich 2014

Subtotal ( $(-$ squared $=0.0 \%, p=0.473$ )

$L$ rhamnosus $G G$

Armuzzi 2001A

Armuzzi 2001日

Cremonini 2002

Miller 2008

Padilla 2013

Thom as 2001

Subtotal (I-squared $=72.7 \%, p=0.003$ )

L reuteri 55730

Cimperman 2011

Ojetti 2012

Scaccianoce 2008

Subtotal (I-squared $=0.0 \%, p=0.611$ )

$\mathrm{L}$ adid L a $5+\mathrm{B}$ ladis $\mathrm{Bb} 12$

Bhalla 2001

Shue 2002

Shue 2006

De Vrese 2011

Mirzaee 2012

Chatterjee 2013

Subtotal (I-squared $=18.7 \%, p=0.292)$

L yhamn R011+L helv R052

Song 2010

Evans 2016

Subtotal ( $(-$-squared $=0.0 \%, p=0.593$ )

$L$ acid $C L 1285+L$ casei $L B C 80 R+L$ rham nosus CLR 2

Beausoleil 2007

Gao 2010a

Gao 2010b

Sampalis 2010

Subtotal (l-squared $=51.1 \%, p=0.105$ )

Overall (I-squared $=47.4 \%, p=0.007$ )

NOTE: Weights are from random effects analysis

.00921
$\mathrm{RR}(95 \% \mathrm{Cl})$

$0.36(0.17,0.79)$

$0.20(0.05,0.84)$

$0.32(0.16,0.63)$

$0.28(0.14,0.55)$

$0.13(0.02,0.94)$

$0.17(0.02,1.27)$

$2.03(0.62,6.59)$

$0.69(0.22,2.19)$

$0.98(0.68,1.42)$

$0.55(0.25,1.18)$

$0.15(0.02,1.12)$

$0.38(0.21,0.70)$

$0.18(0.01,3.43)$

$0.35(0.20,0.61)$

$0.69(0.40,1.20)$

$0.20(0.05,0.88)$

$0.50(0.24,1.03)$

$2.42(0.51,11.48)$

$0.88(0.36,2.12)$

$0.68(0.40,1.14)$

$0.67(0.47,0.94)$

$0.54(0.17,1.74)$

$0.76(0.46,1.27)$

$0.72(0.45,1.15)$

$0.45(0.20,0.98)$

$0.64(0.42,0.97)$

$0.34(0.20,0.60)$

$0.74(0.53,1.02)$

$0.56(0.40,0.79)$

$0.56(0.45,0.70)$

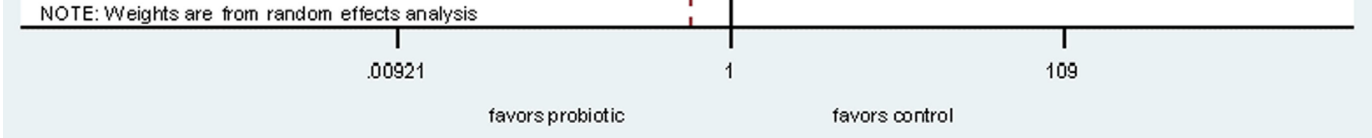

FIGURE 2 | Forest plot of probiotic strain-specificity. Meta-analysis of probiotic strain-specificity for six different Lactobacillus probiotics for the prevention of antibiotic-associated diarrhea in adults. Meta-analysis of 22 randomized, controlled trials by sub-group of probiotic type. Abbreviations: acid, acidophilus; Cl, confidence interval; helv, helveticus; ID, identification; L, Lactobacillus; rhamn, rhamnosus; RR, relative risk.

AAD concluded that "the pooled RR from 62 RCTs indicated a statistically significant association of probiotic administration with reduction in AAD" (64). This conclusion was based on a pooled RR encompassing 32 different types of probiotics, and the pooled studies were a mix of treatment and prevention study designs. Hempel et al. did attempt to pool what they considered similar probiotic types into several subgroups by genus and species. Two strains were appropriately incorporated into separate sub-groups (S. boulardii CNCM I-745 and Enterococcus faecium SF68), while other sub-groups were inappropriately pooled. The subgroup called "Blend" pooled 25 RCTs of 19 different types of multi-strain mixtures and the subgroup "Lactobacillus" pooled 17 RCTs of 11 different species of Lactobacillus. Hempel et al. reported the "Lactobacilli probiotics had significant reduction in the risk of AAD ( $\left.\mathrm{RR}=0.64,95 \% \mathrm{CI} 0.47,0.86, I^{2}=74 \%\right)$ " (64). As shown in Figure 4, a re-analysis of the data using sub-groups of identical strains or mixtures of strains with $\geq 2$ RCTs showed only three subgroups of identical strain types and only two significantly prevent $\mathrm{AAD}$ : L. rhamnosus $\mathrm{GG}(\mathrm{RR}=0.64,95 \%$ CI $0.47,0.87, I^{2}=74 \%$ ) and one of the mixtures (L. acidophilus 


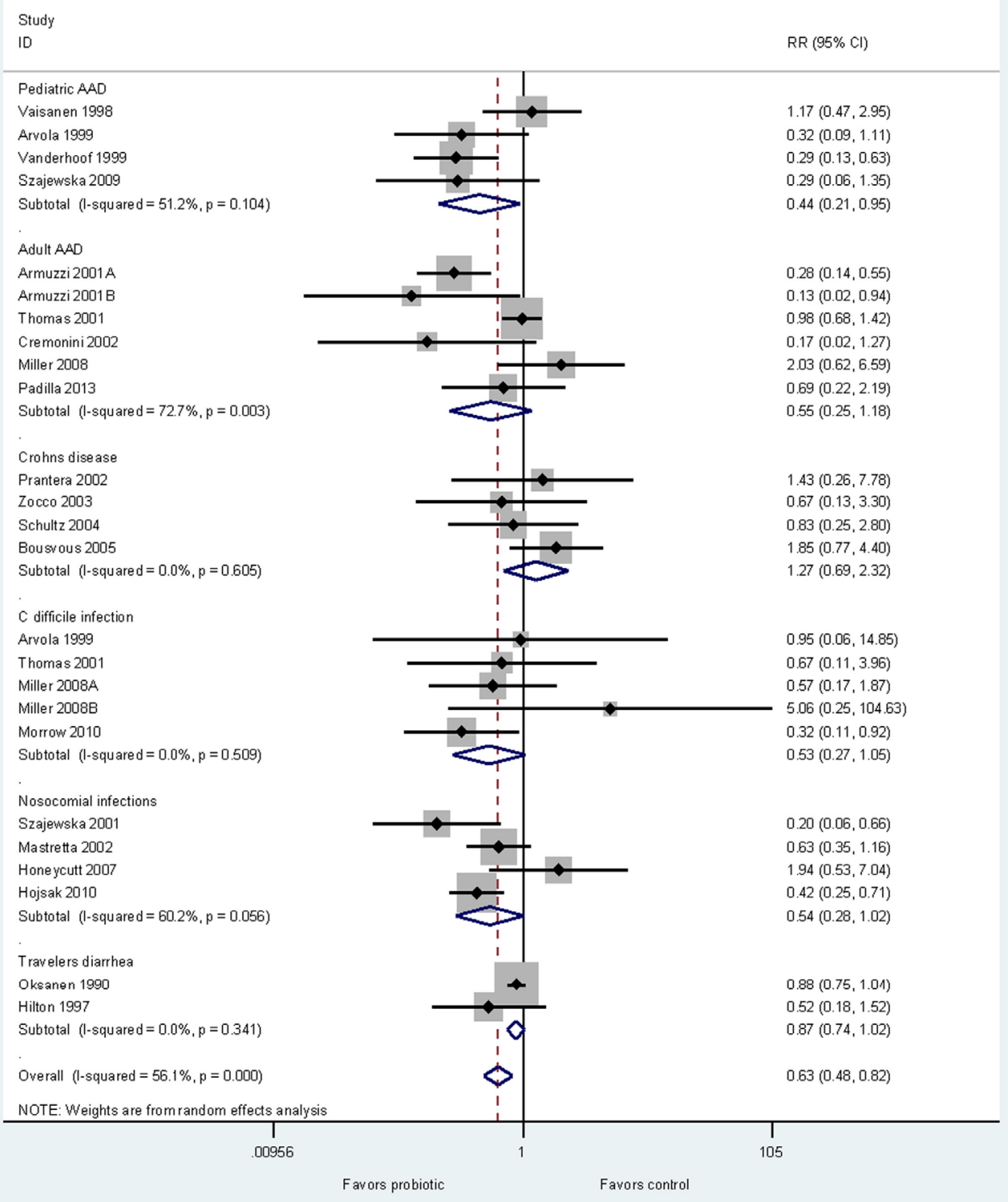

FIGURE 3 | Forest plot of disease-specificity. Meta-analysis of disease-specificity shown for the prevention of six different types of diseases by one strain of probiotic, Lactobacillus rhamnosus GG. A meta-analysis of 24 randomized, controlled trials in adults and children. Abbreviations: AAD, antibiotic-associated diarrhea; C, Clostridium; ID, identification; $\mathrm{Cl}$, confidence interval; $\mathrm{RR}$, relative risk.

CL1285, L. casei LBC80R, and L. rhamnosus CLR2 or “Bio-K+ ${ }^{\circledR ”}$ ) with $\mathrm{RR}=0.61,95 \% \mathrm{CI} 0.48-0.77, I^{2}=38 \%$. The other mixture of Lactobacillus spp. (two RCTs of L. helveticus and L. gasseri mix or "Lactinex ${ }^{\circledR ”}$ ) did not significantly prevent AAD and all other lactobacilli trials reported in Hempel et al. did not have a second confirmatory trial. The importance of analyzing probiotics by species subgroups is confirmed in another meta-analysis of 22 RCTs analyzing 16 different types of probiotics for the prevention of AAD in children (70). The overall pooled data from the 22 trials appeared to confirm that probiotics were effective, but when the appropriate probiotic sub-groups were used, only two types of probiotics (S. boulardii CNCM I-745 pooled from five trials) and L. rhamnosus GG (pooled from four trials) were effective.

Another recent meta-analysis of 26 RCTs concluded "Lactobacilli, mixtures, and $S$. boulardii are effective in preventing C. difficile infections" (66). Closer examination of the "Lactobacilli" subgroup reveals six different Lactobacillus strains and the "mixture" subgroup has five different mixtures of strains. Only one subgroup appropriately pooled data from seven trials using the same strain of probiotic (S. boulardii I-745). As shown in Figure 5, when the "Lactobacilli" and "mixture" groups are appropriately analyzed 


\section{Study}

ID

$\operatorname{RR}(95 \% \mathrm{Cl})$

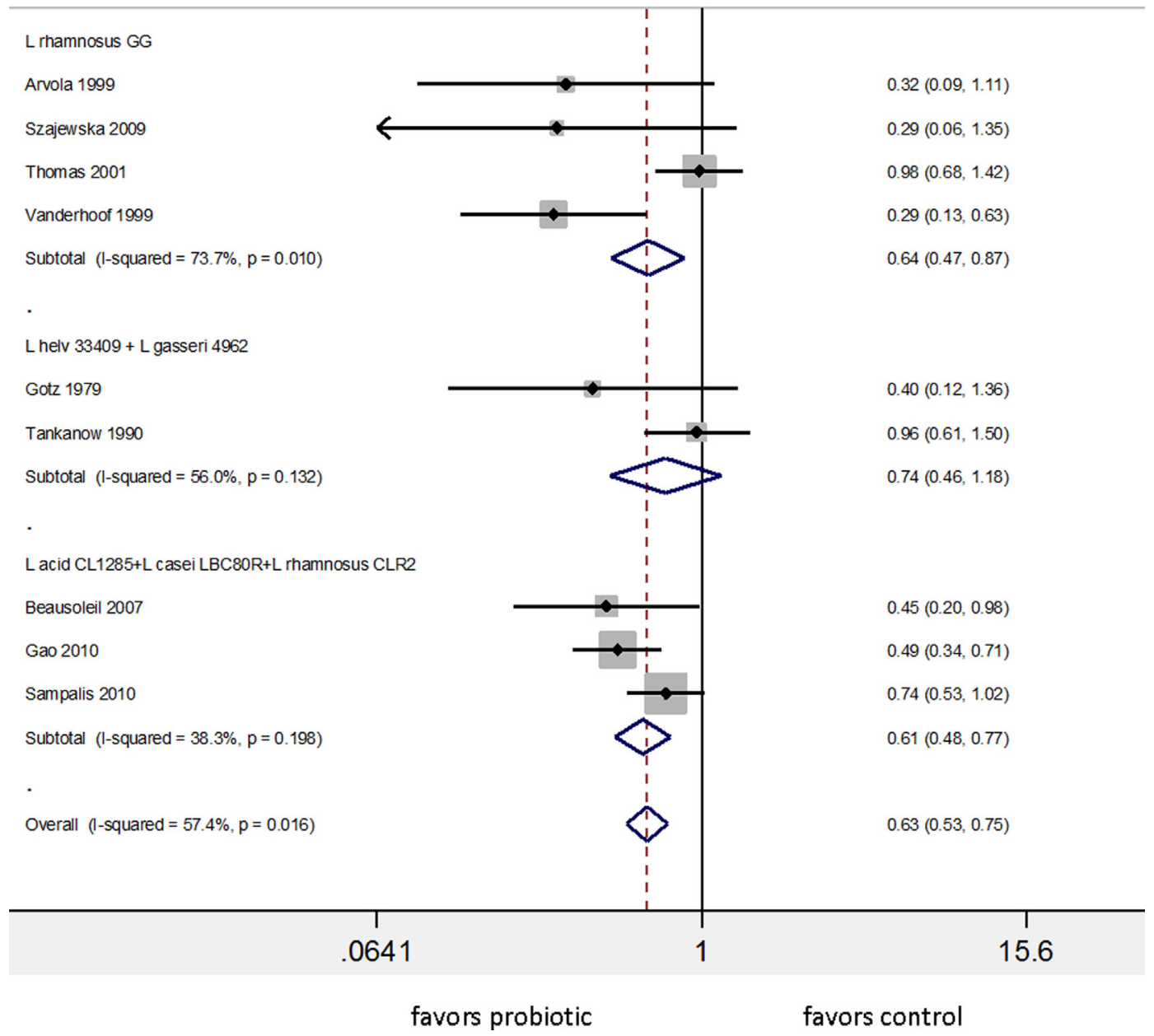

FIGURE 4 | Meta-analysis of nine randomized controlled trials of three different lactobacilli-containing probiotics for the prevention of antibiotic-associated diarrhea in children and adults, sub-grouped by identical strains of Lactobacillus. Modified from the one "lactobacilli" group presented in Hempel et al. (64). Abbreviations: acid, acidophilus; Cl, confidence interval; L, Lactobacillus; helv, helveticus; ID, identification; RR, relative risk.

using the same strain within each sub-group, only two mixtures [(L. acidophilus CL1285, L. casei LBC80R, L. rhamnosus CLR2, or Bio-K+ ${ }^{\circledR}$ ) and a mix of L. acidophilus and Bifidobacterium bifidum (strains not reported)] are significantly effective for preventing C. difficile infections, while the other 10 types quoted as effective in the Lau and Chamberlain paper are not significantly effective or lacked a second, confirmatory trial (71).

A recent meta-analysis of 11 RCTs studying various probiotics for the control of diabetes concluded that "probiotics may be used as an important dietary supplement in reducing the glucose metabolic factors associated with diabetes" (65). The application of this conclusion would have a dramatic impact on health-care systems if probiotics were given to every patient with diabetes. Upon further assessment of the 11 trials, pooling was inappropriate for the mixtures, as there were seven different types of mixtures of strains, but pooling was appropriate for four trials, as there were two trials for L. plantarum DSM21380. However, when the appropriate pooling is subsequently done (72), the analysis shows no strain has a significant effect on diabetes parameters, which was contrary to the original meta-analysis conclusion.

\section{Prevention of Disease}

The variety of different outcome metrics limited the ability to conduct a global meta-analysis for the prevention of all different diseases; therefore, we present a descriptive overview of different probiotic strains for the prevention of various diseases. We found sufficient numbers of RCTs for 10 different types of probiotics for the prevention of four common types of diseases (adult or pediatric AAD, CDI, nosocomial infections, and travelers' diarrhea). Of the 10 types of probiotics with $\geq 2$ RCTs/indication, 93 RCTs were assessed. Seven (70\%) of the 10 probiotic types had strong strength of efficacy, as shown in Table 2. However, not 
Study

ID

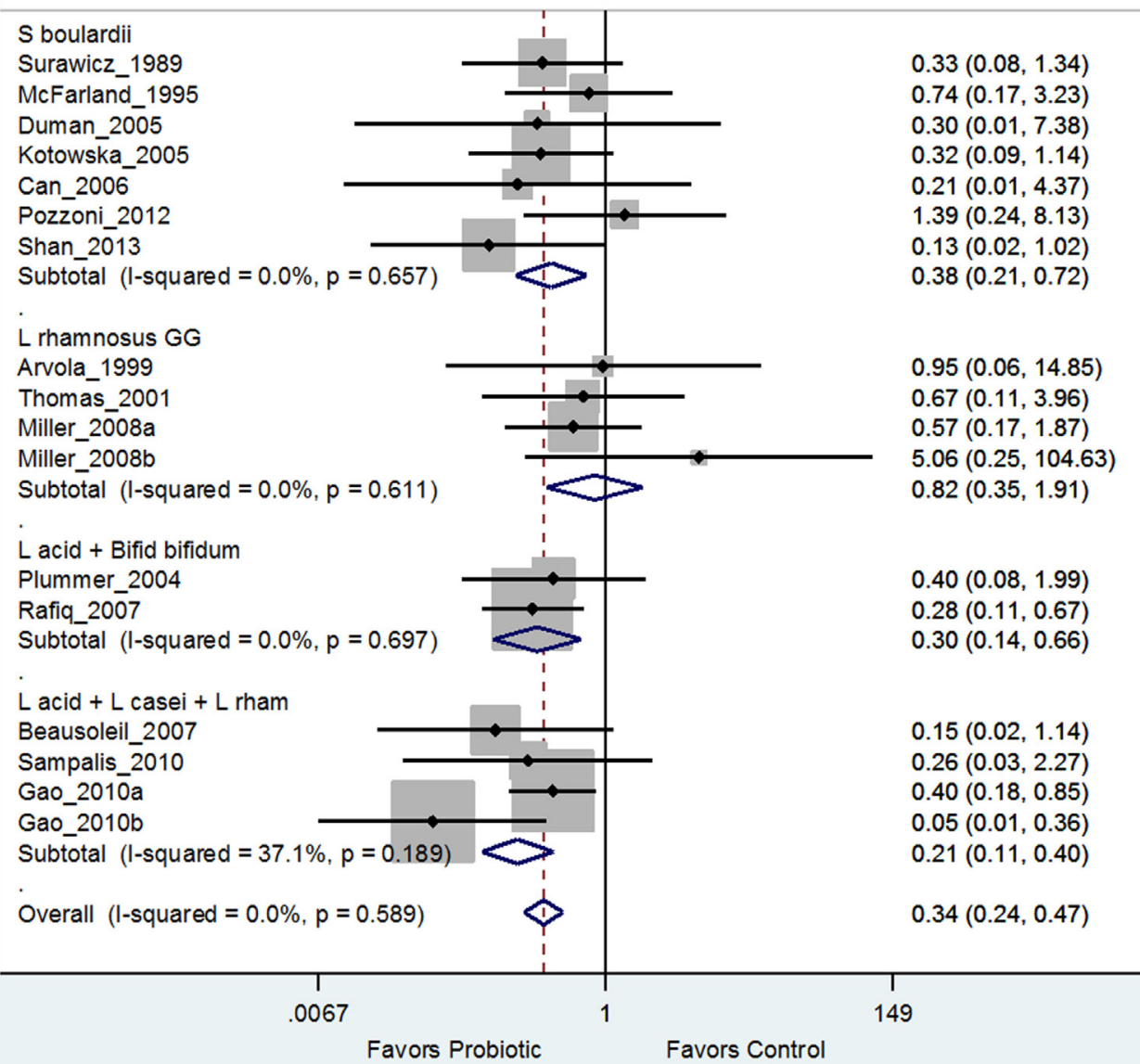

FIGURE 5 | Example of forest plot from an appropriate meta-analysis using probiotic strain subgroup analysis for the prevention of Clostridium difficile infections modified from Lau and Chamberlain (66). Grouping by the same probiotic strain determined that Lactobacillus rhamnosus GG was ineffective, S. boulardii was effective, and only two mixtures were significantly effective (72). Abbreviations: ID, identification; Cl, confidence interval; RR, relative risk; S. boulardii, Saccharomyces boulardii CNCM I-745; L., Lactobacillus; L acid + Bifid bifidum, Lactobacillus acidophilus and Bifidobacterium bifidum strains not reported; L acid + L. casei + L. rhamn, L. acidophilus CL1285 + L. casei LBC80R + L. rhamnosus CLR2, Bio-K+ ${ }^{\oplus}$.

every probiotic was as equally effective for every disease indication and not all strains of probiotics were tested in every type of disease. S. boulardii I-745 has strong evidence for the prevention of adult and pediatric AAD and travelers' diarrhea, but not for the other types of diseases. The mixture of L. acidophilus CL1285, L. casei LBC80R, and L. rhamnosus CLR2 (Bio-K+ ${ }^{\circledR}$ ) also demonstrated significant efficacy for both the prevention of adult AAD and the primary prevention of CDI. Although L. rhamnosus GG had at least two RCTs with significant findings for the prevention of $\mathrm{AAD}$ and nosocomial infections, we also found an equal or more number of trials with non-significant findings. When data from all the trials are pooled for L. rhamnosus GG (Figure 3), significant efficacy is only found for pediatric AAD and not for the other indications. Several other single strain probiotics only had a limited number of RCTs $(n=2-3)$ for the prevention of adult AAD, but had at least two RCTs with significant findings (L. casei DN114001, L. reuteri 55730, Enterococcus faecalis SF68). The two-strain mixture of L. helveticus $\mathrm{R} 52$ and L. rhamnosus R11, Lacidofil ${ }^{\circledR}$ had two RCTs with significant findings for the prevention of pediatric AAD, and had one RCT with non-significant findings (Table 2). Three other types of probiotics with $\geq 2$ RCTs/ disease had more trials with non-significant efficacy findings than trials with significant findings including: C. butryicum 588 , L. reuteri 17938, and a mix of L. acidophilus La5 and B. lactis Bb12.

\section{Treatment of Disease}

A descriptive overview of the efficacy of probiotic strains is also required for the treatment of various diseases, as different outcomes were used by many trials. A total of 135 RCTs for the treatment of five common types of diseases (acute pediatric diarrhea, 
TABLE 2 | Strength of efficacy for probiotics with identified strain designations and at least two randomized, controlled trials with significant findings for the prevention or treatment of disease.

\begin{tabular}{lll}
\hline $\begin{array}{l}\text { Disease } \\
\text { indication }\end{array}$ & Net $\geq 2$ significant & At least two RCTs with \\
& randomized clinical & significant efficacy \\
trials (RCTs) (number of & (number of significant \\
& significant RCTs/non- & RCTs/non-significant \\
significant RCTs) & RCTs)
\end{tabular}

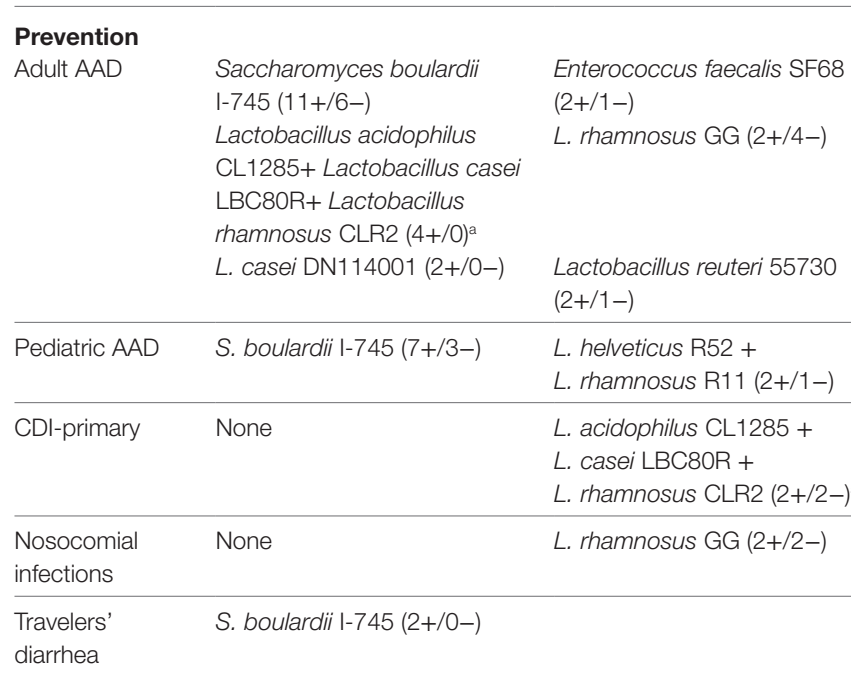

\section{Treatment}

Pediatric acute
L. helveticus $\mathrm{R} 52+$

L. rhamnosus R11 (2+/1-)

L. rhamnosus GG (12+/3-)

L. reuteri DSN $17938(3+/ 0-)$

L. acidophilus LB (3+/1-)

L. casei DN114001 (3+/0-)

VSL\#3 ${ }^{\text {b }}(2+/ 0-)$

Bac. clausii OC/SN/R (3+/1-)

\begin{tabular}{lll}
\hline Irritable bowel & B. infantis 35624 (2+/0-) & L. rhamnosus GG $(2+/ 2-)$ \\
syndrome & L. plantarum 299v (4+/1-) & S. boulardii I I-745 (2+/2-) \\
& L. rhamnosus GG+ L. & VSL\#3 $(2+/ 2-)$ \\
& rhamnosus & \\
& LC705 + B. breve & \\
& Bb99 + Prop. freudenreichii \\
& shermanii Jc (2+/0-)
\end{tabular}

\begin{tabular}{lll}
\hline $\begin{array}{l}\text { Helicobacter } \\
\text { pylori eradication }\end{array}$ & L. helveticus R52 + & $\begin{array}{l}\text { S. boulardii I-745 }(5+/ 11-) \\
\text { L. reuteri } 55730(2+/ 2-)\end{array}$ \\
& & $\begin{array}{l}\text { L. acidophilus La5 }+B . \\
\text { animalis spp. lactis Bb12 } \\
(3+/ 2-)\end{array}$ \\
\hline $\begin{array}{ll}\text { Inflammatory } \\
\text { bowel disease }\end{array}$ & VSL\#3 $^{\text {b }}(8+/ 2-)$ & S. boulardii I-745 (2+/1-) \\
\hline CDI-recurrences & S. boulardii I-745 (2+/0-) &
\end{tabular}

$\overline{A A D}$, antibiotic-associated diarrhea; B., Bifidobacterium; Bac, Bacillus; CDI, clostridium difficile infections; E., Enterococcus; L., Lactobacillus; Prop., Propionibacterium;

S., saccharomyces.

ancludes two dose treatment arms from one trial.

${ }^{b}$ VSL\#3, a mix of eight strains (B. breve, B. longum, B. infantis, L. acidophilus,

L. plantarum, L. paracasei, L. debrueckii spp. bulgaricus, and Streptococcs

thermophilus).

IBS, eradication of $H$. pylori, IBD, and CDI) were found. Of the 17 types of probiotics tested, 11 (65\%) had significant efficacy evidence for the treatment of these diseases. The treatment of acute pediatric diarrhea was the focus for 63 randomized trials. Seven different probiotic strains or mixtures have strong evidence for this indication (Table 2). S. boulardii CMCN I-745 had the most trials with significant efficacy for the treatment of acute pediatric diarrhea. Of 21 RCTs for IBS, three different probiotics had more significant trials compared to non-significant trials for the IBS (B. infantis 35624 , L. plantarum $299 \mathrm{v}$, and a 4 -strain mixture), while three other types of probiotics had an equal number of significant and non-significant trial outcomes (Table 2). Thirty RCTs had at least two trials for each of four different types of probiotics in patients with $H$. pylori infections. One mixture (L. helveticus $\mathrm{R} 52+$ L. rhamnosus $\mathrm{R} 11$ ) had strong evidence for the eradication of H. pylori (Table 2), while three other types of probiotics (S. boulardii I-745, L. reuteri 55730, and a mixture of L. acidophilus $\mathrm{La} 5+B$. animalis spp. lactis $\mathrm{Bb} 12$ ) had at least two RCTs showing a significant reduction in $H$. pylori. Of 13 RCTs for the treatment of IBD, two types of probiotics (VSL\#3 and $S$. boulardii I-745) found significant improvement in IBD symptoms (Table 2). The strongest evidence was found for the VSL\#3 mixture (B. breve BB02, B. longum BL03, B. infantis BI04, L. acidophilus BA05, L. plantarum BP06, L. paracasei BP07, L. helveticus BD08, Strept. thermophiles BT01), with a net of six trials with significant efficacy for the treatment of IBD. Fewer trials were found treating CDI infections that used prevention of recurrences as an outcome, but S. boulardii CNCM I-745 had a net of two significant trials.

\section{DISCUSSION}

Identifying an appropriate probiotic product from the diverse milieu of clinical trial evidence is a daunting challenge. The finding that efficacy is both strain-specific and disease-specific has not been clearly recognized nor acknowledged. Current literature guidelines and expert consensus now recommend reviews and meta-analyses present outcome data in appropriate probiotic strainspecific sub-groups when assessing efficacy outcomes $(73,74)$, but this advice is not uniformly acted upon.

This review is the first paper that we are aware of that determined strain specificity by directly comparing different probiotic strains within the same genus for one disease indication at a time and also examined the differences in efficacy of one probiotic strain for several types of diseases to determine disease-specificity. The findings from this paper support the concept that there is specific probiotic strain and disease-specific clinical efficacy. However, direct comparisons of different strains are rare and multiple trials for the same strain or mixtures for the same disease are uncommon. Despite international recommendations, published metaanalyses and reviews often fail to report strain designations and many inappropriately pool together different strains or species of probiotics into the same subgroup (64-66), or pool probiotics into the same genus level (69) when they conducted their efficacy analysis. When appropriate strain subgroups are created and the data re-analyzed, the findings often find not all the probiotic strains were effective as originally reported $(65,66,71,72)$.

One strategy to account for strain-specificity is to limit the inclusion into meta-analyses to probiotics of the same strain. Several meta-analyses have done this, either by including only trials using S. boulardii CNCM I-745 (75), or L. acidophilus LB (76), or L. reuteri DSM17938 (77). Szajewska et al. included trials 
using L. acidophilus LB and found a significant mean reduction in diarrhea pooled from four trials was $21.6 \mathrm{~h}$ (76). Urbancsek et al. limited their meta-analysis to three trials using $L$. reuteri DSM17938 and also found a significant mean reduction of diarrhea by $24.8 \mathrm{~h}$ (77). Yuan et al. restricted their meta-analysis to trials testing Bifidobacterium infantis 35624 (78), but this study was criticized for including two trials that actually used different strains of B. infantis SD5220 and B. infantis 02 (79).

Another strategy is to appropriately conduct subgroup analyses with the same probiotic strains within each sub-group $(15,16)$. One meta-analysis included 25 RCTs using six different types of single strain probiotics and found only one sub-group (S. boulardii CNCM I-745) significantly improved $H$. pylori eradication rates $(\mathrm{RR}=1.11,95 \% \mathrm{CI} 1.07-1.16)$, while five other strain sub-groups (Clostridium butyricum 588, L. rhamnosus GG, L. acidophilus Lb, L. reuteri ATCC 55730, and L. casei DG) had no significant effect (15). Another meta-analysis of only multistrain mixtures included 19 RCTs with six sub-groups of the same multi-strain mixes (16). Four mixtures significantly increased H. pylori eradication rates (L. acidophilus La5 and B. animalis spp. lactis $\mathrm{Bb} 12$; a mix of L. helveticus $\mathrm{R} 52$ and L. rhamnosus $\mathrm{R} 11$; a mix of L. acidophilus, B. longum and E. faecalis (strains not reported); and an eight-strain mixture). In our review, we found one mixture (L. helveticus $\mathrm{R} 52+$ L. rhamnosus R11) had four RCTs with significant reduction in $H$. pylori and only one with non-significant H. pylori eradication. Three other types of probiotics had RCTs showing significant reduction or non-significant eradication of H. pylori. However, this may not seem as dire as it sounds for the use of probiotics in H. pylori infected patients. A major reason for standard (non-probiotic) treatment failure in these patients is the common occurrence of side effects (diarrhea, nausea, vomiting) associated with the standard antibiotic combination treatments for $H$. pylori, resulting in high rates of non-compliance and failure to complete the entire 10-14 days of therapy. The most valuable use of specific probiotics in these patients is not the direct eradication of $H$. pylori, rather, it is for the reduction of these side-effects (as in prevention of AAD), which allows patients to complete the full course of therapy. Meta-analyses that have assessed the prevention of these side-effects also show probiotic strain specificity indicating some strains are effective for these outcomes, while others are not $(15,16)$.

The clinical application of the appropriate probiotic type for patients is challenging. Our review demonstrates the importance of considering both the probiotic strain specificity and how the probiotic will be applied (disease specificity). A specific probiotic type or formulation that is effective for one disease indication may not be effective for another. Some probiotic strains were found to be effective for preventing disease, but not as a treatment

\section{REFERENCES}

1. Draper K, Ley C, Parsonnet J. A survey of probiotic use practices among patients at a tertiary medical centre. Benef Microbes (2017) 8(3):345-51. doi:10.3920/BM2016.0148

2. Hill C, Guarner F, Reid G, Gibson GR, Merenstein DJ, Pot B, et al. Expert consensus document: the international scientific association for probiotics and prebiotics consensus statement on the scope and appropriate use of the for disease. It was interesting to find probiotic strain-specificity within diseases that may share a similar mechanism of action for probiotic action (such as the modulation of inflammatory response in IBD or IBS). Different probiotic types were more effective for each of the inflammatory disease conditions. Strain and disease specificity may also be dependent on how the probiotic can exert health benefits (for example, differences in mechanisms-of-action) or on the ability to restore the host's normally protective microbiota. This area of research requires further delineation.

Limitations for assessing strain-specificity and diseasespecificity included the limited number of trials using the same strain or mixtures for each specific disease condition, the changing taxonomy of bacterial and fungal species for strain designations, and the lack of a global consensus on strain designations. Strain designations are often not reported in the original publications and involved tracing the history of the probiotic product development to determine strain designations. Meta-analyses and reviews need to pool strains and diseases together only when appropriate. Another limitation was the diversity of outcome metrics used within the same strain for specific diseases, thus limiting the ability to pool outcomes from multiple studies. This is the value of the descriptive overview comparing the number of studies with significant versus non-significant outcomes. Another limitation in this review is that some disease indications are diverse (such as IBD) and some probiotics may be more effective for some subgroups of disease (for example, ulcerative colitis versus Crohn's disease versus pouchitis), but the analysis was limited by the low numbers of trials within those categories.

\section{CONCLUSION}

Evidence from this review shows that there is clear strainspecificity and disease-specificity for probiotic products and every effort should be made to report specific probiotic strains or mixture of strains when analyzing the efficacy and safety of probiotics. The clinical choice of the appropriate probiotic for each patient is challenging and requires both consideration of the type of probiotic strain(s) given and the type of disease indication for which it is needed. However, there is strong evidence for the efficacy of specific probiotics for several diseases (AAD, CDI, IBD, IBS, TD, acute pediatric diarrhea, and for $H$. pylori infections).

\section{AUTHOR CONTRIBUTIONS}

Conceived and designed the review and meta-analysis: LM. Reviewed included papers, wrote and reviewed the paper: LM, $\mathrm{CE}$, and $\mathrm{EG}$.

term probiotic. Nat Rev Gastroenterol Hepat (2014) 11(8):506-14. doi:10.1038/ nrgastro.2014.66

3. McFarland LV. From yaks to yogurt: the history, development and current use of probiotics. Clin Infect Dis (2015) 60(S2):S85-90. doi:10.1093/cid/civ054

4. Cruchet S, Furnes R, Maruy A, Hebel E, Palacios J, Medina F, et al. The Use of probiotics in pediatric gastroenterology: a review of the literature and recommendations by Latin-American experts. Paediatr Drugs (2015) 17(3):199-216. doi:10.1007/s40272-015-0124-6 
5. Szajewska H, Canani RB, Guarino A, Hojsak I, Indrio F, Kolacek S, et al. Probiotics for the prevention of antibiotic-associated diarrhea in children. J Pediatr Gastroenterol Nutr (2016) 62(3):495-506. doi:10.1097/MPG.0000000000001081

6. Khatri I, Tomar R, Ganesan K, Prasad GS, Subramanian S. Complete genome sequence and comparative genomics of the probiotic yeast Saccharomyces boulardii. Sci Rep (2017) 7(1):371-82. doi:10.1038/s41598-017-00414-2

7. Azaïs-Braesco V, Bresson JL, Guarner F, Corthier G. Not all lactic acid bacteria are probiotics, ...but some are. Br J Nutr (2010) 103(7):1079-81. doi:10.1017/ S0007114510000723

8. McFarland LV. Application of meta-analysis to specific research fields: lessons learned. World J of Meta Anal (2015) 3(4):188-92. doi:10.13105/wjma. v3.i4.188

9. Szajewska H. Pooling data on different probiotics is not appropriate to assess the efficacy of probiotics. Eur J Pediatr (2014) 173(7):975. doi:10.1007/ s00431-014-2340-4

10. Goldstein EJ, Tyrrell KL, Citron DM. Lactobacillus species: taxonomic complexity and controversial susceptibilities. Clin Infect Dis (2015) 60(Suppl 2): S98-107. doi:10.1093/cid/civ072

11. Millette M, Nguyen A, Amine KM, Lacroix M. Gastrointestinal survival of bacteria in commercial probiotic products. Intern J Probiotics Prebiotics (2013) $8(4): 149-56$.

12. Domig KJ, Kiss H, Petricevic L, Viernstein H, Unger F, Kneifel W. Strategies for the evaluation and selection of potential vaginal probiotics from human sources: an exemplary study. Benef Microbes (2014) 5(3):263-72. doi:10.3920/ BM2013.0069

13. McFarland LV. Use of probiotics to correct dysbiosis of normal microbiota following disease or disruptive events: a systematic review. BMJ Open (2014) 4(8):e005047. doi:10.1136/bmjopen-2014-005047

14. McFarland LV. Systematic review and meta-analysis of Saccharomyces boulardii in adult patients. World J Gastroenterol (2010) 16(18):2202-22. doi:10.3748/wjg.v16.i18.2202

15. McFarland LV, Malfertheiner P, Huang Y, Wang L. Meta-analysis of single strain probiotics for the eradication of Helicobacter pylori and prevention of adverse events. World J Meta Anal (2015) 3(2):97-117. doi:10.13105/wjma. v3.i2.97

16. McFarland LV, Huang Y, Wang L, Malfertheiner P. Systematic review and meta-analysis: multi-strain probiotics as adjunct therapy for Helicobacter pylori eradication and prevention of adverse events. United European J Gastroenterol (2016) 4(4):546-61. doi:10.1177/2050640615617358

17. Guyatt GH, Oxman AD, Schünemann HJ, Tugwell P, Knottnerus A. GRADE guidelines: a new series of articles in the journal of clinical epidemiology. J Clin Epidemiol (2011) 64(4):380-2. doi:10.1016/j.jclinepi.2010.09.011

18. Donelli G, Vuotto C, Mastromarino P. Phyenotyping and genotyping are both essential to identify and classify a probiotic microorganism. Micro Ecol Health Dis (2013) 3:24. doi:10.3402/mehd.v24i0.20105

19. Dietrich CG, Kottmann T, Alavi M. Commercially available probiotic drinks containing Lactobacillus casei DN-114001 reduce antibiotic-associated diarrhea. World J Gastroenterol (2014) 20(42):15837-44. doi:10.3748/wjg.v20. i42.15837

20. Hickson M, D'Souza AL, Muthu N, Rogers TR, Want S, Rajkumar C, et al. Use of probiotic Lactobacillus preparation to prevent diarrhoea associated with antibiotics: randomised double blind placebo controlled trial. BMJ (2007) 335(7610):80-3. doi:10.1136/bmj.39231.599815.55

21. Cimperman L, Bayless G, Best K, Diligente A, Mordarski B, Oster M, et al. A randomized double blind, placebo controlled pilot study of Lactobacillus reuteri ATCC 55730 for the prevention of antibiotic-associated diarrhea in hospitalized adults. JClin Gastroenterol (2011) 45(9):785-9. doi:10.1097/ MCG.0b013e3182166a42

22. Ojetti V, Bruno G, Ainora ME, Gigante G, Rizzo G, Roccarina D, et al. Impact of Lactobacillus reuteri supplementation on anti-Helicobacter pylori levofloxacin-based second-line therapy. Gastroenterol Res Pract (2012) 2012:740381. doi:10.1155/2012/740381

23. Scaccianoce G, Zullo A, Hassan C, Gentili F, Cristofari F, Cardinale V, et al. Triple therapies plus different probiotics for Helicobacter pylori eradication. Eur Rev Med Pharmacol Sci (2008) 12:251-6.

24. Armuzzi A, Cremonini F, Ojetti V, Bartolozzi F, Canducci F, Candelli M, et al. Effect of Lactobacillus GG supplementation on antibiotic-associated gastrointestinal side effects during Helicobacter pylori eradication therapy: a pilot study. Digestion (2001) 63(1):1-7. doi:10.1159/000051865
25. Armuzzi A, Cremonini F, Bartolozzi F, Canducci F, Candelli M, Ojetti V, et al. The effect of oral administration of Lactobacillus GG on antibiotic-associated gastrointestinal side-effects during Helicobacter pylori eradication therapy. Aliment Pharmacol Ther (2001) 15(2):163-9. doi:10.1046/j.1365-2036.2001. 00923.x

26. Cremonini F, Di Caro S, Covino M, Armuzzi A, Gabrielli M, Santarelli L, et al. Effect of different probiotic preparations on anti-Helicobacter pylori therapy-related side effects: a parallel group, triple blind, placebo-controlled study. Am J Gastroenterol (2002) 97(11):2744-9. doi:10.1111/j.1572-0241.2002. 07063.x

27. Miller M, Florencio S, Eastmond J, Reynolds S. Results of 2 prospective randomized studies of Lactobacillus GG to prevent $C$. difficile infection in hospitalized adults receiving antibiotics. Abstr Intersci Conf Antimicrob Agents (2008):578-9.

28. Padilla-Ruiz M, Fernández Aguiar ME, Arce Nuñez M, Polo Amorín R. [Lactobacillus rhamnosus GG supplementation to reduce side-effects of anti-Helicobacter pylori treatment]. Rev Gastroenterol Peru (2013) 33(2): $121-30$.

29. Thomas MR, Litin SC, Osmon DR, Corr AP, Weaver AL, Lohse CM. Lack of effect of Lactobacillus GG on antibiotic-associated diarrhea: a randomized, placebo-controlled trial. Mayo Clin Proc (2001) 76(9):883-9. doi:10.4065/76.9.883

30. Beausoleil M, Fortier N, Guénette S, L'ecuyer A, Savoie M, Franco M, et al. Effect of a fermented milk combining Lactobacillus acidophilus Cl1285 and Lactobacillus case $i$ in the prevention of antibiotic-associated diarrhea: a randomized, double-blind, placebo-controlled trial. Can J Gastroenterol (2007) 21(11):732-6. doi:10.1155/2007/720205

31. Gao XW, Mubasher M, Fang CY, Reifer C, Miller LE. Dose-response efficacy of a proprietary probiotic formula of Lactobacillus acidophilus CL1285 and Lactobacillus case $\mathrm{LBC}$ 80R for antibiotic-associated diarrhea and Clostridium difficile-associated diarrhea prophylaxis in adult patients. Am J Gastroenterol (2010) 105(7):1636-41. doi:10.1038/ajg.2010.11

32. Sampalis J, Psaradellis E, Rampakakis E. Efficacy of BIO K+ CL1285 in the reduction of antibiotic-associated diarrhea - a placebo controlled double-blind randomized, multi-center study. Arch Med Sci (2010) 6(1):56-64. doi:10.5114/aoms.2010.13508

33. Bhalla A. Randomized placebo-controlled, double blind, multicentric trial on efficacy and safety of probiotic capsules (Lactobacillus acidophilus LA-5 and Bifidobacterium BB-12) for prevention of antibiotic-associated diarrhea in Indian patients [in: abstracts: 40th annual meeting of the American college of clinical pharmacology; September 11-13, 2011; Chicago, IL]. J Clin Pharmacol (2011) 51(9):1327. doi:10.1177/0091270010418046

34. Sheu BS, Wu JJ, Lo CY, Wu HW, Chen JH, Lin YS, et al. Impact of supplement with Lactobacillus- and Bifidobacterium containing yogurt on triple therapy for Helicobacter pylori eradication. Aliment Pharmacol Ther (2002) 16:1669-75. doi:10.1046/j.1365-2036.2002.01335.x

35. Sheu BS, Cheng HC, Kao AW, Wang ST, Yang YJ, Yang HB, et al. Pretreatment with Lactobacillus- and Bifidobacterium-containing yogurt can improve the efficacy of quadruple therapy in eradicating residual Helicobacter pylori infection after failed triple therapy. Am J Clin Nutr (2006) 83:864-9. doi:10.1093/ ajcn/83.4.864

36. De Vrese M, Kristen H, Rautenberg P, Laue C, Schrezenmei J. Probiotic lactobacilli and bifidobacteria in a fermented milk product with added fruit preparation reduce antibiotic associated diarrhea and Helicobacter pylori activity. J Dairy Res (2011) 78(4):396-403. doi:10.1017/S002202991100063X

37. Mirzaee V, Rezahosseini O. Randomized control trial: comparison of triple therapy plus probiotic yogurt vs. standard triple therapy on Helicobacter pylori eradication. Iran Red Crescent Med J (2012) 14(10):657-66.

38. Chatterjee S, Kar P, Das T, Ray S, Gangulyt S, Rajendiran C, et al. Randomised placebo-controlled double blind multicentric trial on efficacy and safety of Lactobacillus acidophilus LA-5 and Bifidobacterium BB-12 for prevention of antibiotic-associated diarrhoea. J Assoc Physicians India (2013) 61(10):708-12.

39. Evans M, Salewski RP, Christman MC, Girard SA, Tompkins TA. Effectiveness of Lactobacillus helveticus and Lactobacillus rhamnosus for the management of antibiotic-associated diarrhoea in healthy adults: a randomised, double-blind, placebo-controlled trial. Br J Nutr (2016) 116(1):94-103. doi:10.1017/ S0007114516001665

40. Song HJ, Kim JY, Jung SA, Kim S, Park H, Jeong Y, et al. Effect of probiotic Lactobacillus (Lacidofil ${ }^{\circledR}$ cap) for the prevention of antibiotic-associated 
diarrhea: a prospective, randomized, double-blind, multicenter study. J Korean Med Sci (2010) 25:1784-91. doi:10.3346/jkms.2010.25.12.1784

41. Abbas Z, Yakoob J, Jafri W, Ahmad Z, Azam Z, Usman MW, et al. Cytokine and clinical response to Saccharomyces boulardii therapy in diarrhea-dominant irritable bowel syndrome: a randomized trial. Eur J Gastroenterol Hepatol (2014) 26(6):630-9. doi:10.1097/MEG.0000000000000094

42. Choi CH, Jo SY, Park HJ, Chang SK, Byeon JS, Myung SJ. A randomized, double-blind, placebo-controlled multicenter trial of Saccharomyces boulardii in irritable bowel syndrome: effect on quality of life. J Clin Gastroenterol (2011) 45(8):679-83. doi:10.1097/MCG.0b013e318204593e

43. Maupas JL, Champemont P, Delforge M. Treatment of irritable bowel syndrome. Double blind trial of Saccharomyces boulardii. Med Chirurgie Dig (1983) 12(1):77-9.

44. Kabir MA, Ishaque SM, Ali MS, Mahmuduzzaman M, Hasan M. Role of Saccharomyces boulardii in diarrhea predominant irritable bowel syndrome. Mymensingh Med J (2011) 20(3):397-401.

45. Pineton de Chambrun P, Neut C, Chau A, Cazaubiel M, Pelerin F, Justen P, et al. A randomized clinical trial of Saccharomyces cerevisiae versus placebo in the irritable bowel syndrome. Dig Liv Dis (2015) 47(2):119-24. doi:10.1016/j. dld.2014.11.007

46. Spiller R, Pélerin F, Cayzeele Decherf A, Maudet C, Housez B, Cazaubiel M, et al. Randomized double blind placebo-controlled trial of Saccharomyces cerevisiae CNCM I-3856 in irritable bowel syndrome: improvement in abdominal pain and bloating in those with predominant constipation. United European Gastroenterol J (2016) 4(3):353-62. doi:10.1177/2050640615602571

47. McFarland LV, Ozen M, Dinleyici EC, Goh S. Comparison of pediatric and adult antibiotic-associated diarrhea and Clostridium difficile infections. World J Gastroenterol (2016) 22(11):3078-104. doi:10.3748/wjg.v22.i11.3078

48. Vaisanen ML, Leskinen M, Siitonen A, Kanervo A, Harila-Saari A, Mottonen M, et al. Occurrence of diarrhea in children receiving oral antibiotics with or without probiotic supplementation with Lactobacillus GG. Micro Ecol Health Dis (1998) 10:199-200.

49. Arvola T, Laiho K, Torkkeli S, Mykkanen H, Salminen S, Maunula L, et al. Prophylactic Lactobacillus GG reduces antibiotic-associated diarrhea in children with respiratory infections: a randomized study. Pediatrics (1999) 104(5):e64. doi:10.1542/peds.104.5.e64

50. Vanderhoof JA, Whitney DB, Antonson DL, Hanner TL, Lupo JV, Young RJ. Lactobacillus GG in the prevention of antibiotic-associated diarrhea in children. J Pediatr (1999) 135(5):564-8. doi:10.1016/S0022-3476(99)70053-3

51. Szajewska H, Albrecht P, Topczewska-Cabanek A. Randomized, double-blind, placebo-controlled trial: effect of Lactobacillus GG supplementation on Helicobacter pylori eradication rates and side effects during treatment in children. J Pediatr Gastroenterol Nutr (2009) 48(4):431-6. doi:10.1097/ MPG.0b013e318182e716

52. Bousvaros A, Guandalini S, Baldassano RN, Botelho C, Evans J, Ferry GD, et al. A randomized, double-blind trial of Lactobacillus GG versus placebo in addition to standard maintenance therapy for children with Crohn's disease. Inflamm Bowel Dis (2005) 11(9):833-9. doi:10.1097/01. MIB.0000175905.00212.2c

53. Prantera C, Scribano ML. Probiotics and Crohn's disease. Dig Liver Dis (2002) 34(Suppl 2):S66-7. doi:10.1016/S1590-8658(02)80168-2

54. Schultz M, Timmer A, Herfarth HH, Sartor RB, Vanderhoof JA, Rath HC. Lactobacillus GG in inducing and maintaining remission of Crohn's disease. BMC Gastroenterol (2004) 4:5. doi:10.1186/1471-230X-4-5

55. Zocco MA, Zileri Dal Verme L, Armuzzi A, Nista EC, Papa A, Candelli M. Comparison of Lactobacillus $G G$ and mesalazine in maintaining remission of ulcerative colitis and Crohn's disease. Abstract \#S1352. digestive disease week meeting, may 17-27, 2003. Gastroenterology (2003) 124(4):A201. doi:10.1016/ S0016-5085(03)81006-5

56. Morrow LE, Kollef MH, Casale TB. Probiotic prophylaxis of ventilatorassociated pneumonia: a blinded, randomized, controlled trial. Am J Respir Crit Care Med (2010) 182(8):1058-64. doi:10.1164/rccm.200912-1853OC

57. Hojsak I, Abdovic S, Szajewska H, Milosevic M, Krznaric Z, Kolacek S. Lactobacillus GG in the prevention of nosocomial gastrointestinal and respiratory tract infections: a randomized, placebo-controlled, double-blind study. Pediatrics (2010) 125(5):e1171-6. doi:10.1542/peds.2009-2568

58. Honeycutt TC, El Khashab M, Wardrop RM III, McNeal-Trice K, Honeycutt AL, Christy CG, et al. Probiotic administration and the incidence of nosocomial infection in pediatric intensive care: a randomized placebo-controlled trial. Pediatr Crit Care Med (2007) 8(5):452-8. doi:10.1097/01.PCC. 0000282176.41134.E6

59. Mastretta E, Longo P, Laccisaglia A, Balbo L, Russo R, Mazzaccara A, et al. Effect of Lactobacillus GG and breast-feeding in the prevention of rotavirus nosocomial infection. J Pediatr Gastroenterol Nutr (2002) 35(4):527-31. doi:10.1097/00005176-200210000-00013

60. Szajewska H, Kotowska M, Mrukowicz JZ, Armanska M, Mikolajczyk W. Efficacy of Lactobacillus $G G$ in prevention of nosocomial diarrhea in infants. J Pediatr (2001) 138(3):361-5. doi:10.1067/mpd.2001.111321

61. Hilton E, Kolakowski P, Singer C, Smith M. Efficacy of Lactobacillus $G G$ as a diarrheal preventive in travelers. J Travel Med (1997) 4(1):41-3. doi:10.1111/ j.1708-8305.1997.tb00772.x

62. Oksanen PJ, Salminen S, Saxelin M, Hamalainen P, Ihantola-Vormisto A, Muurasniemi-Isoviita L, et al. Prevention of travellers' diarrhoea by Lactobacillus GG. Ann Med (1990) 22(1):53-6. doi:10.3109/07853899009147242

63. Goldenberg JZ, Lytvyn L, Steurich J, Parkin P, Mahant S, Johnston BC. Probiotics for the prevention of pediatric antibiotic-associated diarrhea. Cochrane Database Syst Rev (2015) (12):CD004827. doi:10.1002/14651858

64. Hempel S, Newberry SJ, Maher AR, Wang Z, Miles JN, Shanman R, et al. Probiotics for the prevention and treatment of antibiotic-associated diarrhea: a systematic review and meta-analysis. JAMA (2012) 307(18):1959-69. doi:10.1001/ jama.2012.3507

65. Sun J, Buys NJ. Glucose- and glycaemic factor-lowering effects of probiotics on diabetes: a meta-analysis of randomised placebo-controlled trials. Br J Nutr (2016) 115(7):1167-77. doi:10.1017/S0007114516000076

66. Lau CS, Chamberlain RS. Probiotics are effective at preventing Clostridium difficile-associated diarrhea: a systematic review and meta-analysis. Int J Gen Med (2016) 9:27-37. doi:10.2147/IJGM.S98280

67. Lu M, Yu S, Deng J, Yan Q, Yang C, Xia G, et al. Efficacy of probiotic supplementation therapy for Helicobacter pylori eradication: a meta-analysis of randomized controlled trials. PLoS One (2016) 11(10):e0163743. doi:10.1371/ journal.pone. 0163743

68. Lv Z, Wang B, Zhou X, Wang F, Xie Y, Zheng H, et al. Efficacy and safety of probiotics as adjuvant agents for Helicobacter pylori infection: a meta-analysis. Exp Ther Med (2015) 9(3):707-16. doi:10.3892/etm.2015.2174

69. Zhang Y, Lixiang L, Guo C, Mu D, Feng B, Zuo X, et al. Effects of probiotic type, dose and treatment duration on irritable bowel syndrome diagnosed by Rome III criteria: a meta-analysis. BMC Gastroenterol (2016) 16:62. doi:10.1186/s12876-016-0470-z

70. McFarland LV, Goh S. Preventing pediatric antibiotic-associated diarrhea and Clostridium difficile infections with probiotics: a meta-analysis. World J Meta Anal (2013) 1(3):102-20. doi:10.13105/wjma.v1.i3.102

71. McFarland LV. An observation on inappropriate probiotic sub-group classifications in the meta-analysis by Lau and Chamberlain. Int J Gen Med (2016) 9:333-6. doi:10.2147/IJGM.S119970

72. McFarland LV. Importance of subgroup analysis in probiotic meta-analyses. Letter to the editor. Br J Nutr (2016) 116:375-6. doi:10.1017/S0007114516002026

73. Glanville J, King S, Guarner F, Hill C, Sanders ME. A review of the systematic review process and its applicability for use in evaluating evidence for health claims on probiotic foods in the European Union. Nutr J (2015) 14:16-24. doi:10.1186/s12937-015-0004-5

74. Hill C, Scott K, Klaenhammer TR, Quigley E, Sanders ME. Probiotic nomenclature matters. Gut Microbes (2016) 7(1):1-2. doi:10.1080/19490976.2015.1 127484

75. Szajewska H, Horvath A, Kołodziej M. Systematic review with meta-analysis: Saccharomyces boulardii supplementation and eradication of Helicobacter pylori infection. Aliment Pharmacol Ther (2015) 41(12):1237-45. doi:10.1111/ apt.13214

76. Szajewska H, Ruszczyński M, Kolaček S. Meta-analysis shows limited evidence for using Lactobacillus acidophilus LB to treat acute gastroenteritis in children. Acta Paediatr (2014) 103(8):249-55. doi:10.1111/apa.12487

77. Urbancsek H, Kazar T, Mezes I, Neumann K. Results of a double-blind, randomized study to evaluate the efficacy and safety of antibiophilus in patients with radiation-induced diarrhoea. Eur J Gastroenterol Hepatol (2001) 13:391-6. doi:10.1097/00042737-200104000-00015

78. Yuan F, Ni H, Asche CV, Kim M, Walayat S, Ren J. Efficacy of Bifidobacterium infantis 35624 in patients with irritable bowel syndrome: a meta-analysis. 
Curr Med Res Opin (2017) 33(7):1191-7. doi:10.1080/03007995.2017. 1292230

79. Allen AP, Clarke G, Cryan JF, Quigley EMM, Dinan TG. Bifidobacterium infantis 35624 and other probiotics in the management of irritable bowel syndrome. Strain specificity, symptoms and mechanisms. Curr Med Res Opin (2017) 33(7):1349-51. doi:10.1080/03007995.2017.1322571

Conflict of Interest Statement: LM, CE, and EG serves or has served on the Bio-K Plus advisory board. EG is on the infection control and medical advisory board for Kindred Healthcare System. LM is or has been a paid lecturer for Biocodex and Lallemand and is a board member of the Biocodex Microbiome Foundation.

Copyright $\odot 2018$ McFarland, Evans and Goldstein. This is an open-access article distributed under the terms of the Creative Commons Attribution License (CC BY). The use, distribution or reproduction in other forums is permitted, provided the original author(s) and the copyright owner are credited and that the original publication in this journal is cited, in accordance with accepted academic practice. No use, distribution or reproduction is permitted which does not comply with these terms. 